\title{
Consistent leverpress avoidance responding by rats
}

\author{
JOHN H. HULL, JAMES S. MYER, and GREGORY J. SMITH \\ Kent State University, Kent, Ohio 44242
}

\begin{abstract}
Three groups of rats were presented with a retractable lever, followed 10 sec later by shock of $.5,1.0$, or $2.0 \mathrm{~mA}$, respectively. Leverpresses occurring during the 10-sec interval resulted in immediate retraction of the lever and avoidance of shock. If the lever was not pressed within 10 sec, shock was administered until the lever was pressed or for a maximum of $20 \mathrm{sec}$, at which time the lever retracted and shock terminated. Within 200 trials, most rats avoided $80 \%-90 \%$ of shocks, regardless of shock intensity.
\end{abstract}

Many investigators (e.g., D'Amato \& Schiff, 1964; Meyer, Cho, \& Weseman, 1960; Reynierse, 1972; Scheuer \& Sutton, 1973) have reported minimal success in attempting to condition leverpress avoidance responding in rats. In most experiments, trial onset is signaled by an increase in illumination or presentation of a tone. If no leverpress occurs within a predetermined interval, aversive shock is administered until the lever is pressed. The usual result has been that a small percentage of rats eventually make leverpress avoidance responses on a majority of the trials, but most rats develop and maintain short-latency escape responses rather than avoiding.

At least two procedures have produced fairly high levels of leverpress avoidance responding by rats. D'Amato and his associates (D'Amato, Keller, \& DiCara, 1964; D'Amato \& Fazzaro, 1966) reported that rats exposed to intermittent shock when they failed to avoid attained much higher rates of leverpress avoidance responding than did rats which received continuous shock on nonavoidance trials. D'Amato and Fazzaro (1966) proposed that intermittent shock leads to high levels of avoidance responding because escape responses occur in the absence of shock, facilitating generalization of responding to the preshock avoidance phase. Other investigators (Scheuer \& Sutton, 1973) have successfully obtained moderate levels of leverpress avoidance responding by some rats by using extensive training of leverpressing for positive reinforcers prior to introduction of the escape-avoidance procedure.

The studies reported above employed a fixed lever as the response manipulandum, and a visual or auditory stimulus change as a signal for trial onset. The purpose of the present study was to examine leverpress avoidance

This research was supported by National Science Foundation Grant GB-13939. We thank Charles G. Bertsch and David Gerzog-Thomas for their assistance in the conduct of this experiment. Requests for reprints should be sent to James S. Myer, Department of Psychology, Kent State University, Kent, Ohio 44242. responding by rats, using a procedure in which a retractable lever was the response manipulandum, and presentation of that lever was the signal for trial onset.

\section{METHOD}

\section{Subjects}

Subjects were 24 experimentally naive adult male Long-Evans rats, obtained from Huntingdon Farms. The rats were individually caged, with constant illumination and continuous access to food and water.

\section{Apparatus}

Each of four $20 \times 23.5 \times 19-\mathrm{cm}$-high rodent test cages was enclosed in a sound-attenuating chamber containing a red $25-\mathrm{W}$ incandescent light. A Foringer solenoid-operated retractable lever was mounted $5.3 \mathrm{~cm}$ from the floor at the center of one end wall of each test cage. When the levers were presented, they protruded $12-15 \mathrm{~mm}$ into the cages, and between trials they retracted to a position $3 \mathrm{~mm}$ outside the cages. Scrambled shock was provided by Grason-Stadler model E1064GS shock generators. Lever and shock presentations and recording of leverpress latencies to the nearest $.1 \mathrm{sec}$ were controlled by electromechanical equipment in an adjacent room. White masking noise was continuously present in the experimental room during all sessions.

\section{Procedure}

Three groups of eight rats underwent identical procedures except for the intensity of shock administered after failures to avoid. Three days before the first experimental session, the rats were placed in the test cages for $50 \mathrm{~min}$. On this day, the levers were not introduced into the cages, and no shocks were presented. On each of the next 2 days, the rats were exposed to 100 lever presentations. On each trial, the lever was presented for a maximum of $30 \mathrm{sec}$ and then retracted if no leverpress occurred during that period. When a leverpress occurred, the lever retracted immediately. No shocks were presented during these sessions. The interval between successive lever presentations averaged $60 \mathrm{sec}$, with intervals between 35 and $100 \mathrm{sec}$ arranged in an irregular sequence.

During Experimental Session 1, the lever was presented on the same schedule as during the 2 preexperimental days. If the lever was not pressed within $10 \mathrm{sec}$ of introduction into the cage, shock was presented for $20 \mathrm{sec}$ or until a leverpress occurred. Leverpresses during the first $10 \mathrm{sec}$ of lever presentation resulted in immediate lever retraction and avoidance of shock. On trials in which no avoidance response occurred, the three groups of 


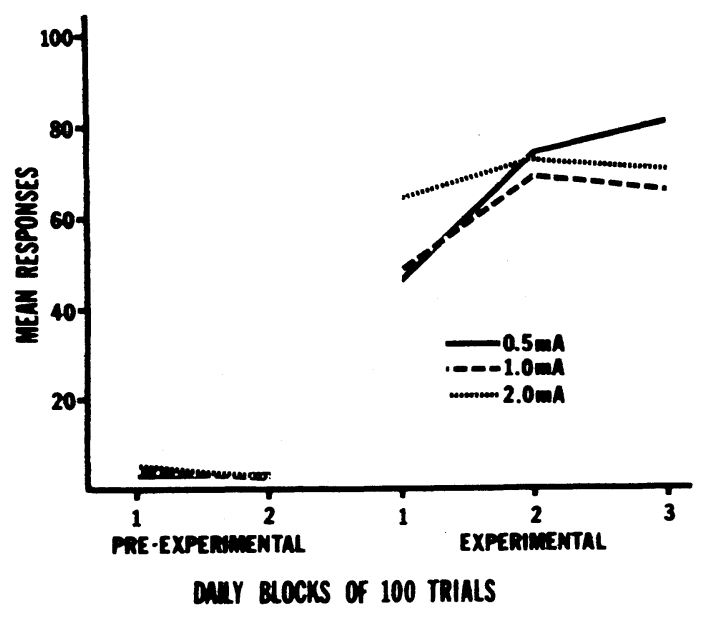

Figure 1. Mean responses on daily blocks of 100 trials during 30-sec lever presentations on Preexperimental Days 1 and 2 and mean avoidance responses on Experimental Days 1-3. Independent groups of rats received the indicated shock intensities upon failure to avoid on the 3 experimental days.

rats were exposed to shock intensities set at $.5,1.0$, or $2.0 \mathrm{~mA}$, respectively. A leverpress during the $20 \mathrm{sec}$ of shock resulted in immediate shock termination and lever retraction. Experimental sessions continued for 3 days. On the 4 th experimental day, the rats were initially exposed to 50 trials with the same contingencies as on the 3 previous days. During the last 50 trials on the 4 th experimental day, the lever retraction contingency remained the same, but no shocks were presented.

\section{RESULTS}

The mean number of responses for each group on the 2 pre-experimental days and the mean number of avoidance responses on the three successive daily 100-trial experimental sessions are shown in Figure 1. Comparisons of leverpressing in the three groups across the 2 pre-experimental days indicated that there were no significant differences between the groups in mean number of leverpresses. Analysis of variance comparing avoidance responding across the 3 experimental days showed a significant effect of experimental days $F(2,42)=8.58, p<.01$, but neither a significant effect of experimental group $(\mathrm{F}<1)$, nor a significant Group by Days interaction $F(4,42)=1.03, p>.05$. There were no significant differences between the three groups in numbers of leverpresses made with $10 \mathrm{sec}$ of lever presentation during the 50 extinction trials at the end of the 4th experimental day, group means being $34.3,21.6$, and 36.8 responses for the .5-, 1.0-, and 2.0-mA groups, respectively. Finally, there were no significant differences between groups in latency of avoidance responses on any experimental day, and median response latencies for all groups on all 3 experimental days were under $1 \mathrm{sec}$.

\section{DISCUSSION}

The results of the present study contrast with those of other leverpress avoidance experiments. The rats did not receive extensive pretraining with positive reinforcement for leverpressing, nor was discontinuous shock used during the experimental sessions. Nevertheless, high levels of leverpress avoidance responding were obtained when a retractable lever was used both as the stimulus signaling trial onset and as the response manipulandum. Additionally, the present experiment did not show that variations in shock intensity influence avoidance responding. Marone (Note 1) also found no effect of shock intensity upon leverpress avoidance responding. The shock intensities used in the present experiment fall well within the range of intensities across which he found no differential effects either in acquisition or extinction of avoidance responding.

Failures to obtain consistent leverpress avoidance responding by rats in previous studies have been explained in a variety of ways. One hypothesis (Meyer et al., 1960) is that a substantial change in proprioceptive stimulation is needed for any type of avoidance responding to rapidly develop. It is difficult to see how the procedure of the present study provides much more change in proprioceptive stimulation than do fixed-lever procedures, nor how such an explanation can handle the comparatively rapid acquisition of leverpress avoidance responding by species such as guinea pigs and hamsters (Pearl, 1963).

Other explanations of failures to obtain consistent leverpress avoidance responding are that leverpressing is not a "species-specific defense reaction" (Bolles, 1970), or that rats are "contraprepared" (Seligman, 1970) to make leverpress avoidance responses. According to Bolles' explanation, freezing and running are high-probability responses when a rat encounters a noxious stimulus and, as such, should easily be conditioned as avoidance responses. On the other hand, responses such as leverpressing are relatively uncommon when a rat encounters a noxious stimulus and should therefore be more difficult to condition as avoidance responses. It is possible to hypothesize after the fact that pressing a retractable lever is an example of yet another species-specific defense reaction, perhaps an "attack" response. However, there seems to be no compelling reason to assume that pressing a retractable lever is any more a species-specific defense reaction than is pressing a fixed lever. Similarly, it is difficult to maintain that a rat is less "contraprepared" (Seligman, 1970) to press a retractable lever than it is to press a fixed lever.

It is difficult to reconcile the results of the present study with any prevailing hypothesis concerning the ease of conditioning various avoidance responses. Perhaps entry of the retractable lever into the test cage is a very salient cue for avoidance responding. It remains for future studies to determine why the procedure of the present experiment led to rapid acquisition and consistent maintenance of avoidance responding by rats.

\section{REFERENCE NOTES}

1. Marone, F. J. Effects of shock intensity on acquisition and extinction of discriminated lever-press avoidance responding. Paper presented at the annual meeting of the Eastern Psychological Association. New York. 1975.

\section{REFERENCES}

Bolles, R. C. Species-specific defense reactions and avoidance learning. Psychological Review. 1970, 77, 32-48.

D. Amato, M. R.. \& Fazzaro, J. Discriminated lever-press avoidance learning as a function of type and intensity of shock. Journal of Comparative and Physiological Psychology. 1966. 61. 313-315.

DAmato, M. R., Keller, D., \& DiCara, L. Facilitation of discriminated avoidance learning by discontinuous shock. Journal of Comparative and Physiological Psychology, 1964, 58. 344-349. 
D'Aмато, M. R., \& Schiff, D. Long-term discriminated avoidance performance in the rat. Journal of Comparative and Physiological Psychology, 1964, 57, 123-126.

Meyer, D. R., Cho, C., \& Weseman, A. F. On problems of conditioning lever-press avoidance responses. Psychological Review, 1960, 67, 224-228.

PEARL, J. Avoidance learning in rodents: A comparative study. Psychological Reports, 1963, 12, 139-145.

REYNIERSE, J. H. Differentiation of escape and avoidance responding in rats. Journal of Comparative and Physiological Psychology, 1972, 79, 165-170.
Scheuer, C., \& Sutton, C. O. Discriminative vs. motivational interpretations of avoidance extinction: Extensions to learned helplessness. Animal Learning and Behavior, 1973, 1, 193-197.

Seligman, M. E. P. On the generality of the laws of learning. Psychological Review, 1970, 77, 406-418.

(Received for publication June 5, 1975.) 